\title{
The effects of low level laser therapy on Staphylococcus aureus infected third-degree burns in diabetic rats ${ }^{1}$
}

\author{
Reza Ranjbar', Mohammad Ashrafzadeh Takhtfooladi ${ }^{I I}$ \\ DOI: http://dx.doi.org/10.1590/S0102-865020160040000005 \\ IFull Professor, Molecular Biology Research Center, Baqiyatallah University of Medical Sciences, Tehran, Iran. Design and supervised all phases of \\ the study. \\ IIPhD, Young Researchers and Elites Club, Science and Research Branch, Islamic Azad University, Tehran, Iran. Conception and design of the study; \\ acquisition, analysis and interpretation of data; manuscript writing.
}

\begin{abstract}
PURPOSE: To characterize the effects of low-level laser (LLL) on third-degree burn wounds which were infected with Staphylococcus aureus (S. aureus) in diabetic rats.

METHODS: Thirty streptozotocin-induced diabetic rats were divided into two groups: the control and the LLL groups. Third-degree burns were induced using a heated metal rod, and then, were contaminated with $S$. aureus. The wounds in the LLL group were irradiated with a LLL $(685 \mathrm{~nm})$ daily for five consecutive days, starting three days after the induction. The wound area was measured at $3,5,8,14$ and 21 days after burning. At the end of trial, the skin samples were harvested.

RESULTS: Reduction in wound areas in the LLL and control groups were significantly different only on the $21^{\text {st }}$ day $(p<0.05$ ). The mean bacterial numbers in the LLL group were significantly lower $(\mathrm{p}<0.05)$ than those in the control group. The number of macrophages, new blood vessels, fibroblast, and elevated collagen deposition in the LLL group significantly increased compared to the control group $(p<0.05)$. The mean breaking strength of scars in the control group was significantly lower ( $<<0.05)$ than that of the LLL group.
\end{abstract}

CONCLUSION: The low-level laser improved the healing of $S$. aureus third-degree burn infections in diabetic rats.

Key words: Low-Level Light Therapy. Staphylococcus aureus. Burns. Rats. 


\section{Introduction}

Skin wound healing, especially in diabetic patients, is one of the most important issues in medical sciences and has always been of interest to researchers and clinicians who have put much effort into accelerating the wound healing process, preventing infections, and increasing the tensile strength of the healing tissue after recovery ${ }^{1}$. The delay in the healing of wound infections in diabetic patients is a problem caused by neuropathy and impaired tissue blood flow ${ }^{2}$. According to the World Health Organization, the number of diabetic patients is rising ${ }^{3}$. With that in mind, it seems that in addition to the important measures in the prevention of diabetes, we should try to choose the most effective treatment of diabetic wounds in order to avoid complications such as infections, amputations, or slow recovery.

Staphylococcus aureus ( $S$. aureus) is an important cause of nosocomial infections in most health centers ${ }^{4}$. The indiscriminate use of antibiotics in the last decades has led to the emergence of resistant strains of bacteria. Methicillin-resistant $S$. aureus is among the most important cases that are resistant to all beta-lactam antibiotics. Today the treatment of infections caused by these bacteria is one of the main problems of health centers. That's why new methods must be used to defeat infections caused by these bacteria. One of these methods can be the use of Low Level Laser (LLL). Understanding the bactericidal effect of the LLL can be appropriate to treat patients with infectious wounds. LLL therapy can be used alongside other treatments associated with injuries resulting in wounds ${ }^{5,6}$. The use of LLL therapy as a photonic treatment to stimulate or accelerate the healing of the wounds started by Mester in 1970, and further studies have been conducted on its effects on wound healing since then ${ }^{7-11}$. Studying the interaction between laser and tissue is a very important issue in treatment. The most important mechanism proposed in this field is the effect of LLL on shortening the tissue inflammation and accelerating the proliferation phase, anti-bacterial effect, effect on mitochondrial function of cells, increasing the blood supply to tissues and cell membrane potential changes which eventually can accelerate wound healing process ${ }^{12-14}$.

Given that the effects of laser highly depend on its physical features, such as wave-length, pulse/energy, energy density, and delivery system, and since most researches have been limited to non-diabetic wounds focusing on histology and practically, there is no comprehensive study on the impact of the laser on diabetic infected wounds especially $S$. aureus (one of the 5 most common causes of nosocomial infections, particularly in burn wound infections). Therefore, a comprehensive study on the protective effect of LLL on this type of infected diabetic wounds appears necessary. The aim of this research is to study the effect of LLL therapy on third-degree burn wounds infected with $S$. aureus in diabetic rats by evaluating the microbiological, histopathological, and biomechanical analysis of the healing tissue.

\section{Methods}

The experimental procedures with the animals used in the present study were approved by the Ethics Committee of the Islamic Azad University, Faculty of Veterinary Medicine, Tehran, Iran, under the reference code 032-4/2015.

In this study, thirty male adult Wistar rats weighing 200 to $250 \mathrm{~g}$ provided by the Pasteur Institute of Iran were used. The rats were kept in individual plastic cages under suitable conditions (temperature $25 \pm 2{ }^{\circ} \mathrm{C}$, relative humidity 50 to $60 \%$, and a 12-hour light-dark cycle). The animals were fed a standard pelleted rodent diet and water ad libidum. Subjects were randomly divided into two experimental groups i.e. the control group and the LLL group. Each group consisted of fifteen rats five of which were used for bacterial load determination, five for histopathological analysis, and five for breaking strength measurement.

\section{Experimental induction of diabetes in rats}

Diabetes was induced by a single injection of streptozotocin $\left(200 \mathrm{mg} / \mathrm{kg}\right.$, i.p. $\left.{ }^{15}\right)$ in the volume of $0.2 \mathrm{ml}$, to the overnight fasting rats. Streptozotocin was dissolved in normal saline. Animals' blood glucose levels were measured via a commercial glucometer. 14 days later, rats with blood glucose level of $\geq 300 \mathrm{mg} / \mathrm{dL}^{16}$ were considered as diabetic models.

\section{Experimental protocol}

On day zero, each rat was weighed using a digital scale, and then, ketamine $50 \mathrm{mg} / \mathrm{kg}$ and xylazine $10 \mathrm{mg} / \mathrm{kg}$ were used intraperitoneally for general anesthesia. After the anesthesia, the dorsal hair of the rats' right thoracic region was shaved and cleaned with povidone-iodine. Third-degree burns were induced using a metal rod ( $2 \mathrm{~cm}$ diameter) heated to $80-85^{\circ} \mathrm{C}$ which was exposed for $20 \mathrm{~s}^{17}$. After the burning procedure, the drug nalbuphine hydrochloride $(2 \mathrm{mg} / \mathrm{kg}$ ) was administered at 12-h intervals for two consecutive days for analgesic prophylaxis. The skin wound area was contaminated with one aliquot of $50 \mu \mathrm{L}$ of a saline solution containing approximately $5 \times 10^{7} \mathrm{CFU} / \mathrm{mL}$ of $S$. aureus.

\section{Laser irradiation}

A $685 \mathrm{~nm} \mathrm{InGaAlP}\left(15 \mathrm{~mW}, 3 \mathrm{~J} / \mathrm{cm}^{2}\right.$, spot of 0.028 $\mathrm{cm}^{2}$, Teralaser; DMC ${ }^{\circledR}$ São Carlos-SP, Brazil) was used in the 
present study. The optical power was calibrated using Newport Multifunction Optical Meter model 1835C. The infected wounds were irradiated daily for 5 consecutive days, starting on the $3^{\text {rd }}$ day post-induction, and always in the mornings. To administer laser treatment, the burned area was divided into for equal parts. The tip of the laser source was contact with the surface of the burn at the center of each part, and directed perpendicularly to the target tissue for the designated time i.e., 75s. The control group animals underwent sham irradiation with the turned off equipment.

\section{Macroscopic analysis}

In each group, the clinical assessment of wound size and appearance was performed by taking digital image using a digital camera which was kept at a constant distance of $30 \mathrm{~cm}$ from the injured area, and had the same resolution in the same lighting conditions on days $0,3,5,8,14$ and 21 . For the purpose of determining the size and the appearance of the wound area through image analysis, the Image J software was used.

At the end of the trial, euthanasia was performed using an overdose of anesthetic drugs before tissue samples were removed.

\section{Bacteriological analysis}

A $1 \mathrm{~cm} \times 2 \mathrm{~cm}$ skin tissue sample, including the wound, was homogenized in $1 \mathrm{ml}$ phosphate-buffered saline (3500 rpm, $5 \mathrm{~min})$ and was then centrifuged $(10.000 \times \mathrm{g})$ for $10 \mathrm{~min}$. The supernatant was collected and plated on TSA agar plates. After incubation in the dark at $37^{\circ} \mathrm{C}$ for $48 \mathrm{~h}$, the number of colonies was counted. The bacterial load measurement was done by multiplying the number of colonies with dilution factor and the volume of supernatant obtained during the tissue homogenization which was presented as $\log \mathrm{CFU} / \mathrm{ml}^{18}$.

\section{Breaking strength analysis}

To measure the breaking strength of scars, a strip of skin $7 \mathrm{~cm}$ long and with the same widths of the wound diameter was carefully removed by a scalpel in the manner that the wound was located at the middle of the strip. The sample was placed in a gauze soaked with normal saline and was sent to the laboratory inside a container with lid for tensiometric test. Then, the segment was pulled at both ends by two clamps using a machine for biomechanical assays (Zwick/Roell, Ulm, Germany) until being broken.

\section{Histopathological analysis}

The skin specimens from the wounds and surrounding healthy skins were removed with a scalpel. Then, the samples were fixed in a $10 \%$ formaldehyde solution for $48 \mathrm{~h}$ and later embedded in paraffin blocks. Serial $5 \mu \mathrm{m}$ sections were cut and stained by hematoxylin and eosin. The histological sections were evaluated by one pathologist who was blinded to the experiment as suggested by Gál et al. ${ }^{19}$ by the following scale: $0,1,2$, and 3 (Table 1).

TABLE 1 - Explanation of scale used in evaluation of histological sections.

\begin{tabular}{cccccccc}
\hline Scale & Epithelialization & PMNL & Macrophages & Fibroblasts & New collagen & Neo-angiogenesis \\
\hline $\mathbf{0}$ & Thickness of cut edges & Absent & Absent & Absent & Absent & Absent \\
$\mathbf{1}$ & Migration of epithelial cells & Mild & Mild & Mild & Mild & Mild \\
$\mathbf{2}$ & Bridging of the incision & Moderate & Moderate & Moderate & Moderate & Moderate \\
$\mathbf{3}$ & Complete regeneration & Marked & Marked & Marked & Marked & Marked \\
\hline
\end{tabular}

\section{Statistical analysis}

SPSS statistical software (version 18) was used to perform the Mann-Whitney U test and an ANOVA test to compare the two groups. Values of $\mathrm{p}<0.05$ were considered as statistically significant.

\section{Results}

No complications were encountered during the study. All of the rats tolerated procedures well and survived until the end of the experiment.

The macroscopic evaluations of the wound area in the LLL group were performed on the $3^{\text {rd }} 5^{\text {th }}, 8^{\text {th }}, 14^{\text {th }}$ and $21^{\text {st }}$ days after the injury and the results were compared to those of the control group (Figure 1). In the beginning days, the mean scores of the wound areas for the two groups were not statistically significant. Reduction in wound areas in the LLL and the control group was significantly different only on the $21^{\text {st }}$ day $(\mathrm{p}<0.05)$. 


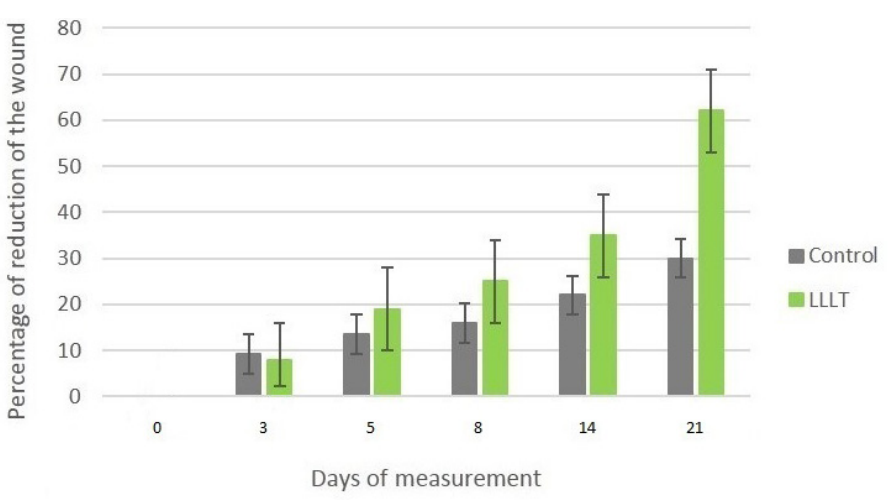

FIGURE 1 - Percentage of reduction of the area of the third-degree burn wound experimentally induced in diabetic rats. The control group and laser treated group with $3 \mathrm{~J} / \mathrm{cm}^{2}$.
The mean bacterial score for the LLL group $\left(0.65 \times 10^{1} \pm\right.$ $\left.0.33 \times 10^{1} \mathrm{CFU} / \mathrm{ml}\right)$ was significantly lower $(\mathrm{p}<0.05)$ than that of the control group $\left(9.2 \times 10^{7} \pm 1.5 \times 10^{7} \mathrm{CFU} / \mathrm{ml}\right)$.

In the microscopic examination of skin samples (Table 2), LLL therapy caused a significant increase $(p<0.05)$ in the number of macrophages, fibroblast, new blood vessels, and elevated collagen deposition in comparison to the control group (Figure 2).

TABLE 2 - Semi-quantitative evaluation of histological structures after low level laser therapy (LLLT).

\begin{tabular}{ccccccc}
\hline Group & Epithelialization & PMNL & Macrophages & Fibroblasts & New collagen & Neo-angiogenesis \\
\hline LLLT & $1.02 \pm 0.3^{*}$ & $1.1 \pm 0.2^{*}$ & $1.1 \pm 0.3^{*}$ & $1.8 \pm 0.4^{*}$ & $1.5 \pm 0.7^{*}$ & $1.2 \pm 0.5^{*}$ \\
Control & $0.2 \pm 0.1$ & $1.91 \pm 0.5$ & $1.9 \pm 0.5$ & $0.9 \pm 0.6$ & $0.6 \pm 0.5$ & $0.6 \pm 0.2$ \\
\hline
\end{tabular}

$* p<0.05$.
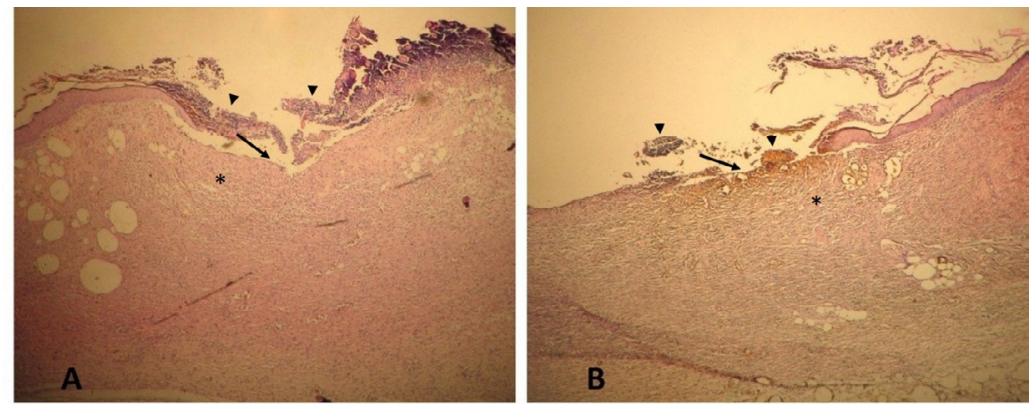

FIGURE 2 - Histological sections of control (A), and low level laser $(\mathbf{B})$ groups at 21 days post wounding. respectively (HE, $\times 40)$. Note that the injured area is devoid of epidermis (arrows). Cell debris (arrowheads) are deposited on the skin surface. The connective tissue of the superficial dermis is formed by a loose connective containing active fibroblasts (*).

The mean score for the breaking strength of wound scars in the control group was significantly lower $(\mathrm{p}<0.05)$ than that of the LLL group (Figure 3).

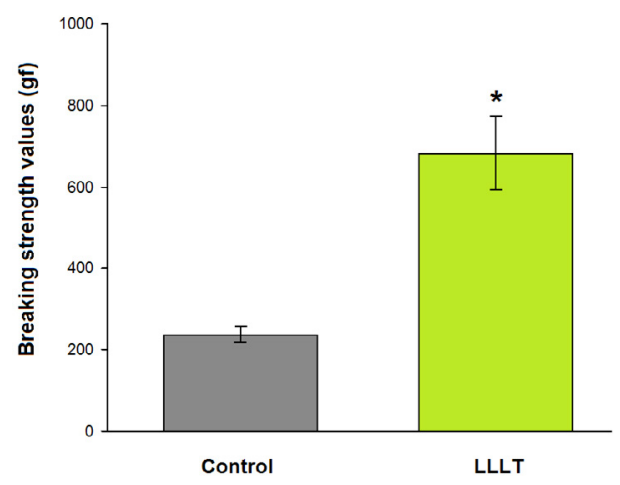

FIGURE 3 - The effect of low level laser therapy (LLLT) on breaking strength at 21 days after induction of infectious burns in diabetic rats. LLLT was performed daily from 3 to 8 days after wounding. *Statistically significant difference $(\mathrm{p}<0.05)$ in comparison with the control.

\section{Discussion}

The employment of LLL therapy was initially proposed by Mester et $a .^{7}$ as a treatment method. They demonstrated the positive effects of LLL on the wound healing process. Their research led to an increasing interest in understanding this technology as well as its applications ${ }^{7}$. It was suggested that the LLL increases cell metabolism, stimulates oxidative phosphorylation and reduces local inflammatory response, positively changing electrophysiological properties of the irradiated tissue ${ }^{20}$. LLL application also has the effect of biomodulation, which activates or inhibits the physiological processes and has biochemical and metabolic effects via photochemical and/or photophysical processes $^{21}$. Studies conducted on the efficacy of the LLL therapy in cutaneous wound had difficulties in drawing consistent 
conclusions due to a lack of coordination between different laser systems and the selected features. As a result, several papers with quite different and sometimes contradictory results have been published $^{22,23}$.

In a study by Yu et $a l .{ }^{8}$, the argon laser with a wavelength of $630 \mathrm{~nm}$ was used on diabetic wounds in a twenty-day healing process, the positive effect of which was eventually reported. Furthermore, Reddy et al. ${ }^{9}$ reached similar results in a study on wound healing process in diabetic mice. In another study, Maiya et $a .^{24}$ performed the LLL therapy on wounded diabetic rats using laser with the wavelength of $632.8 \mathrm{~nm}$ and the dose of 4.8 $\mathrm{J} / \mathrm{cm}^{2}$ five days a week. They used biochemical and histological analyses to evaluate the wound healing scale. They reported that in a group under laser therapy, the wound healing process has been accelerated 18 days whereas in the control group, this duration took up to 95 days $^{24}$. The macroscopic and microscopic results from this study on the positive role of LLL therapy in wound healing are similar to the results of the previous studies. The comparison between wound areas in the LLL and the control groups showed a significant difference only at the end of the third week. In the pathological study of skin samples, the average rate of the tissue damage in the treatment group was lower than that of the control group at the end of the $21^{\text {st }}$ day.

In addition, tensile strength of the skin has been addressed in several studies for examining the speed of wound healing. A study has been conducted on the diabetic rats using He$\mathrm{Ne}$ laser with the wavelength of $830 \mathrm{~nm}$ by Stadler et al. ${ }^{1}$ Wounds had been irradiated from the $1^{\text {st }}$ to the $4^{\text {th }}$ day in the first group and from the $3^{\text {th }}$ to the $7^{\text {th }}$ day in the second group. Higher tensile strength in this study was witnessed in the $3^{\text {rd }}$ to $7^{\text {th }}$ day which shows the significant difference between the LLL and the control groups. In the line with preliminary study, this study documented that the control group showed significant reduction in the breaking strength of wound scars produced in the skin when compared to the LLL group.

The anti-bacterial effect of the LLL therapy is one of the treatment mechanisms which are compatible with its antiinflammatory effect. In a way, the LLL treatment could shorten the inflammation duration by eliminating the bacteria so the inflammation reduces in the treatment ${ }^{14,22}$. It is reported that the LLL therapy will result in inhabitation of infectious conditions and reduction in the inflammation by inhibiting the bacteria proliferation and stimulating the phagocytic activity of leukocytes in in vitro ${ }^{25,26}$. The bactericidal effect of the LLL therapy is also observed in dentistry. In addition to conducting studies on the antibacterial effect of LLL, Kersler et al. ${ }^{27}$ used laser on dental implants in order to avoid microbial platelet aggregation in 2002. Bayat et al. ${ }^{28}$ also concluded in their research that the LLL treatment has an antibacterial effect on the third-degree burn wounds. Ferreira et al. ${ }^{29}$ also studied the LLL with $3 \mathrm{~J} / \mathrm{cm}^{2}$ intensity effect on infected wounds in Paracoccidioidomycotic cases. In Ferreira's study the laser treatment was performed on the $7^{\text {th }}, 8^{\text {th }}$ and $9^{\text {th }}$ days of the infection and samples were collected from the wounds on the $10^{\text {th }}$ day. Results showed that in the treatment group, in addition to wound healing, the macrophages and lymphocytes rate increased in comparison to the control group ${ }^{24}$. Wilson et al. ${ }^{30}$ used an IGAlAr laser against $S$. aureus, and the results revealed reduction in the number of colonies. Nussbaum ${ }^{31}$ also studied the effects of LLL with the wavelength of 630,810 , and $660 \mathrm{~nm}$ on in $1-50 \mathrm{~J} / \mathrm{cm}^{2}$ intensity on $S$. aureus, pseudomonas, and E. coli which were taken from infected wounds. The best antibacterial results appeared in the lasers with $630 \mathrm{~nm}$ wavelength and $1-20 \mathrm{~J} / \mathrm{cm}^{2}$ intensity. Our results are in line with the previous studies which showed that the application of $685 \mathrm{~nm}$ LLL can significantly reduce the growth of $S$. aureus.

\section{Conclusions}

Low-level laser herapy induced the destruction of $S$. aureus in the third-degree burns of diabetic rats. Moreover, the present study revealed that the LLL irradiation at $685 \mathrm{~nm}$ promoted a reduction of the inflammatory reaction and improved collagen deposition, thereby ameliorated the healing of this type of injury.

\section{References}

1. Stadler I, Lanzafame RJ, Evans R, Narayan V, Dailey B, Buehner N, Naim JO. 830nm irradiation increases the wound tensile strength in a diabetic murine model. Laser Surg Med. 2001;28(3):220-6. PMID: 11295756.

2. Al-Watban FA, Zhang XY, Andres BL. Low-level laser therapy enhances wound healing in diabetic rats: a comparison of different lasers. Photomed Laser Surg. 2007 Apr;25(2):72-7. PMID: 17508840 .

3. Hawkins D, Houreld N, Abrahamse H. Low level laser therapy (LLLT) as an effective therapeutic modality for delayed wound healing. Ann N Y Acad Sci. 2005 Nov;1056:486-93. PMID: 16387711.

4. Khan HA, Ahmad A, Mehboob R. Nosocomial infections and their control strategies. Asian Pac J Trop Biomed. 2015;5(7):509-14. doi:10.1016/j.apjtb.2015.05.001.

5. Wilson M, Pratten J. Sensitization of Staphylococcus aureus to killing by low power laser light. J Antimicrob Chemother. 1994 Mar;33:619-24. PMID: 8040125.

6. Khosravi AD, Rostamian J, Moradinegad P. Investigation of bactericidal effect of low level laser of gallium-aluminium-arsenide on cariogenic species of streptococci and lactobacillus. Med Sci. 2008;8(6):579-82. doi: 10.3923/jms.2008.579.582. 
7. Posten W, Wrone DA, Dover JS, Arndt KA, Silapunt S, Alam M. Low-level laser therapy for wound healing: mechanism and efficacy. Dermatol Surg. 2005 Mar;31(3):334-40. PMID: 15841638.

8. Yu W, Naim JO, Lanzafame RJ. Effects of photostimulation on wound healing in diabetic mice. Laser Med Surg. 1997;20(1):56-63. PMID: 9041509.

9. Reddy GK, Stehno-Bittel L, Enwemeka CS. Laser photostimulation accelerates wound in diabetic rats. Wound Repair Regen. 2001 MayJun;9(3):248-55. PMID: 11472621.

10. Whelan HT, Buchmann EV, Dhokalia A, Kane MP, Whelan NT, Wong-Riley MT, Eells JT, Gould LJ, Hammamieh R, Das R, Jett M. Effect of NASA Light-emitting diode irradiation on molecular change for wound healing in diabetic mice. J Clin Laser Med Surg. 2003 Apr;21(2):67-74. PMID: 12737646.

11. Forney R, Mauro T. Using Lasers in diabetic wound healing. Diabetes Technol Ther. 1999 Summer;1(2):189-92. PMID: 11475291.

12. Yasukawa A, Hrui H, Koyama Y, Nagai M, Takakuda K. The effect of low reactive-low level laser therapy (LLLT) with Helium-Neon laser on operative wound healing in rat model. J Vet Med Sci. 2007 Aug;69(8):799-806. PMID: 17827885.

13. $\mathrm{Hu}$ WP, Wang JJ, Yu CL, Lan CC, Chen GS, Yu HS. HeliumNeon laser irradiation Stimulates Cell Proliferation through Photostimulatory effects in mitochondria. J Invest Dermatol. 2007 Aug;127(8):2048-57. PMID: 17446900.

14. Hoseini Sanati M, Torkaman G, Hedayati M, Mokhtari M. Effect of Ga-As $(904 \mathrm{~nm})$ and He-Ne (632.8 $\mathrm{nm})$ laser on the improvement of biomechanical characteristics recovery in full thickness wound. Lasers Med. 2010 Spring;7(1):6-13.

15. Baluchnejadmojarad T, Roghani M, Khaste khodaie Z. Evaluation of the effect of chronic administration of Silymarin on thermal and chemical hyperalgesia in an experimental model of diabetic neuropathy in male rats. Iranian J Endocrinol Metabolism. 2010 Jan;5:583-9.

16. Lim J, Sanders RA, Snyder AC, Eells JT, Henshel DS, Watkins JB 3rd. Effects of low-level light therapy on streptozotocin-induced diabetic kidney. J Photochem Photobiol B. 2010 May 3;99(2):10510. PMID: 20356759.

17. Ganjali A, Sotoudeh A, Jahanshahi A, Takhtfooladi MA, Bazzazan A, Roodbari N, Harati MP. Otostegia persica extraction on healing process of burn wounds. Acta Cir Bras. 2013 Jun;28(6):407-11. PMID: 23743676

18. Zhao G, Usui ML, Underwood RA, Singh PK, James GA, Stewart PS, Fleckman P, Olerud JE. Time course study of delayed wound healing in a biofilm-challenged diabetic mouse model. Wound Repair Regen. 2012 May-Jun;20(3):342-52. doi: 10.1111/j.1524475X.2012.00793.x.

19. Gál P, Vidinský B, Toporcer T, Mokrý M, Mozes S, Longauer F, Sabo J. Histological assessment of the effect of laser irradiation on skin wound healing in rats. Photomed Laser Surg. 2006 Aug;24(4):4808. PMID: 16942428.

20. Rocha JAM, Vieira BJ, Andrade LCF, Aarestrup FM. Effects of lowlevel laser therapy on the progress of wound healing in humans: the contribution of in vitro and in vivo experimental studies. J Vasc Bras. 2007;6:257-66. doi: 10.1590/S1677-54492007000300009.

21. Henriques ACG, Cazal C, JFL. Ação da laserterapia no processo de proliferação e diferenciação celular: revisão da literatura. Rev Col Bras Cir. 2010;37:295-302.

22. Meyerholz DK, Piester TL, Sokolich JC, Zamba GK, Light TD. Light Morphological parameters for assessment of burn severity in an acute burn injury rat model. Int J Exp Pathol. 2009 Feb;90(1):2633. doi: 10.1111/j.1365-2613.2008.00617.x.

23. von Bathen LC, Paula JB, Cielinski J, Pilonetto M, von Bahten LC. Effects of low-level laser in in vitro bacterial culture and in vivo infected wounds. Rev Col Bras Cir. 2014 Jan-Feb;41(1):49-55. PMID: 24770774

24. Maiya AG, Kumar P, Nayak S. Photo-stimulatory effect of low energy helium-neon laser irradiation on excisional diabetic wound healing dynamics in wistar rats. Indian J Dermatol. 2009;54(4):3239. doi: 10.4103/0019-5154.57606.

25. Cumming J, Kloth LC, McCulloch JM, Feedar J. Role of light in wound healing. Wound healing: alternative in management. Philadelphia: FA Davis Co; 1990.

26. Silva DC, Plapler H, Costa MM, Silva SR, Sá Mda C, Silva BS. Low level laser therapy (AlGaInP) applied at $5 \mathrm{~J} / \mathrm{cm}^{2}$ reduces the proliferation of Staphylococcus aureus MRSA in infected wounds and intact skin in rats. An Bras Dermatol. 2013 Jan-Feb;88(1):50-5. PMID: 23539003.

27. Kreisler M, Kohnen W, Marinello C, Götz H, Duschner H, Jansen B, d'Hoedt B. Bactericidal effect of the Er:YAG laser on dental implant surfaces: an in vitro study. J Periodontol. 2002 Nov;73(11):1292-8. PMID: 12479633.

28. Bayat M, Vasheghani MM, Razavi N. LLLT has antibacterial and angiogenic properties in burns. J Photochem Photobiol B. 2006 Jan;30. PMID: 16455266.

29. Ferreira MC, Gameiro J, Nagib PR, Bitro VN, Vasconcellos Eda D, Verinaud L. Effect of Low Intensity Helium-Neon (He-Ne) laser irradiation on experimental paracoccidioidomycotic wound healing dynamic. Photochem Photobiol. 2009 Jan-Feb;85(1):227-33. PMID: 18764901.

30. Wilson M, Yianni C. Killing of methicillin-resistant Staphylococcus aureus by low-power laser light. J Med Microbiol. 1995 Jan;42(1):626. PMID: 7739027.

31. Nussbaum EL, Lilge L, Mazzulli T. Effects of 630-, 660-, 810-, and 905-nm laser irradiation delivering radiant exposure of 1-50 J/cm2 on three species of bacteria in vitro. J Clin Laser Med Surg. 2002 Dec;20(6):325-33. PMID: 12513919.

\section{Correspondence:}

Mohammad Ashrafzadeh Takhtfooladi

Young Researchers and Elites Club

Science and Research Branch

Islamic Azad University, Tehran, Iran

Phone: +98 9121590428

Fax: +982144629353

dr_ashrafzadeh@yahoo.com

Received: Dec 10, 2015

Review: Feb 11, 2016

Accepted: Mar 15, 2016

Conflict of interest: none

Financial sources: none

${ }^{1}$ Research performed at Molecular Biology Research Center, Baqiyatallah University of Medical Sciences, Tehran, Iran. 